\title{
ANÁLISE DAS EMPRESAS DE COWORKING DE TERESINA-PI
}

ANALYSIS OF COWORKING COMPANIES FROM TERESINA-PI

Recebido em: 23 nov. 2020

Aprovado em: 13 fev. 2021

Versão do autor aceita publicada online: $13 \mathrm{fev} .2021$

Publicado online: 25 jun. 2021

Como citar esse artigo - American Psychological Association (APA):

Oliveira, C. M. R., \& Santos, M. S. F. (2023, jan./mar). Análise das empresas de coworking de Teresina-PI. Exacta, 21(1), 199-223. https://doi.org/10.5585/exactaep.2021.18755

Submeta seu artigo para este periódico

Processo de Avaliação: Double Blind Review

Editor: DDr. Luiz Fernando Rodrigues Pinto

Dados Crossmark 



\title{
○ ANÁLISE DAS EMPRESAS DE COWORKING DE TERESINA-PI
}

\section{ANALYSIS OF COWORKING COMPANIES FROM TERESINA-PI}

\author{
(iD) Clarissa Maria Rodrigues de Oliveira ${ }^{1}$ \\ (iD) Maria Socorro Ferreira dos Santos ${ }^{2}$
}

Resumo: O Coworking consiste em uma modalidade de trabalho, o qual pessoas compartilham um mesmo espaço que apresenta uma infraestrutura completa de escritório, dividindo despesas e fomentando o networking. Neste sentido, o presente trabalho propôs avaliar os projetos de implantação das empresas de coworking de Teresina$\mathrm{Pl}$, descrevendo o modelo de negócio, identificando o perfil demográfico dos coworkers, particularidades do negócio na região e o nível de qualidade destes pela percepção do cliente. A metodologia utilizada possui natureza básica e indutiva. Dessa forma, realizou-se visitas a escritórios compartilhados, entrevista com os gestores e aplicação de questionários aos usuários do serviço. Dos resultados apresentados, dentre os motivos mais apontados pela opção do coworking e como vantagens destacaram-se a redução de custos e o networking proporcionados, ademais, segundo usuários, os coworkings da região oferecem um serviço de qualidade, contudo, gestores relataram sobre a dificuldade de captar clientes e da cultura comodista do teresinense de desejar possuir um escritório próprio apesar dos altos custos de manutenção.

Palavras chaves: coworking. trabalho colaborativo. modelo de negócio.

Abstract: Coworking consists of a type of work, in which people share the same space that presents a complete office infrastructure, sharing expenses and fostering networking. In this sense, the present work proposed to evaluate the implantation projects of the coworking companies of Teresina-PI, describing the business model, identifying the demographic profile of the coworkers, particularities of the business in the region and the quality level of these according to the customer's perception. The methodology used is basic and inductive in nature. Thus, visits were made to shared offices, interviews with managers and questionnaires were applied to service users. From the results presented, among the most pointed reasons for the coworking option and as advantages, the cost reduction and the networking provided stood out, in addition, according to users, coworkings in the region offer a quality service, however, managers reported about the difficulty to attract customers and the commodite culture of the people of Teresina to wish to have their own office despite high maintenance costs.

Keywords: coworking. collaborative work. business model.

\footnotetext{
1 Universidade Federal do Piauí (UFPI) / Centro de Tecnologia (CT) / Curso de Engenharia de Produção / Graduanda no Curso de Engenharia de Produção / Centro de Tecnologia na Universidade Federal do Piauí. Teresina - Piauí - Brasil - clamarirodrigues@hotmail.com https://www.ufpi.br/ct

2 Universidade Federal do Piauí (UFPI) / Centro de Tecnologia (CT) / Curso de Engenharia de Produção - Possui graduação em Engenharia Química pela Universidade Federal de Campina Grande (2003), Graduação em Licenciatura Plena em Química pela Universidade Estadual da Paraíba (2003), Mestrado em Engenharia Química pela Universidade Federal do Rio Grande do Norte (2005) e Doutorado em Engenharia Química pela Universidade Federal de Campina Grande (2013). Professora da Universidade Federal do Piauí no Curso de Engenharia de Produção. Atuo na área de Engenharia Ambiental, Sustentabilidade, Cadeia de suprimentos. Teresina - Piauí - Brasil. socorroferreira@ufpi.edu.br - https://www.ufpi.br/ct
} 
1 Introdução

Nos últimos 20 anos, as empresas têm evoluído cada vez mais seus projetos de escritórios físicos com estruturas tradicionais para novos escritórios com aspectos mais abertos e contemporâneos. Esses novos designs de local de trabalho pretendem aprimorar o fluxo de comunicação, a colaboração além das fronteiras e a inovação (Bouncken, Aslam e Qui, 2021).

Neste sentido Brown (2017) considera que espaços de coworking (CWS) e a prática associada de coworking, surgiram em inúmeras formas e em vários contextos para desafiar criticamente os conceitos do local de trabalho e do localização do trabalho criativo, ao mesmo tempo em que confronta a forma de como os trabalhadores criativos interagem e se relacionam uns com os outros, bem como com espaço em que se encontram.

Segundo Luo e Chan (2020) esse fenômeno surgiu por várias razões, e a literatura existente propõe principalmente uma explicação da perspectiva do usuário que considera esse desenvolvimento como a organização espacial inevitável do trabalho no pós-fordismo, com comunidades em busca de trabalho individual e transbordamento de conhecimento. A ascensão da economia do conhecimento, da classe criativa e da digitalização econômica (Moriset, 2013) transformou profundamente a organização do trabalho. Aumentos substanciais na terceirização de trabalho e colaboração entre empresas enxutas fomentaram a individualização do trabalho e o rápido desenvolvimento de start-ups (Florida, Adler e Mellander, 2017), visto que trabalho flexível e start-ups são vulneráveis em termos de estresse, solidão e oportunidades de trabalho instáveis.

Neste sentido os espaços de coworking oferecem suporte psicológico, senso de comunidade, transbordamento de conhecimento e excelente potencial para oportunidades de colaboração (Spinuzzi, 2012)

Reuschke, Clifton e Fisher (2021) avaliam que os coworkings refletem mudanças significativas na atividade econômica relacionadas a um aumento no trabalho de conhecimento digital e o aumento associado na localização independete do trabalho, bem como o aumento de trabalhadores profissionais autônomos (Waters-Lynch, Potts, Butcher

Dodson e Hurley, 2016 ).

Essa modalidade de escritório compartilhado, além do baixo custo e o fornecimento de uma estrutura adequada para atender pequenas empresas, startups, autônomos, freelancers, empresários emergentes e teletrabalhadores, oferece um ambiente de trabalho alternativo para profissionais que buscam formas de laborar diferentes da estrutura tradicional de organização, mas também procurando por amenizar o isolamento profissional, bem como estimular o compartilhamento de ideias e experiências e ofertar o networking (Medina e Krawulski, 2015). 
Bouncken, Aslam e Qiu (2020) buscaram analisar os padrões institucionais no CWS e mostrar como suas configurações se relacionam com a satisfação no trabalho e para isso entrevistaram 328 pessoas que utilizam CWS em 26 cidades nos EUA, Alemanha e na China e identificaram configurações de padrões institucionais sobre satisfação no trabalho associadas a um senso de compreensão comunidade, autonomia, participação, multiplicidade de ligações e criação de conhecimento mútuo. Alta satisfação no trabalho pode ocorrer em três configurações diferentes relacionadas a a) habitação de agilidade, b) habitação de conhecimento ec) social habitação. Nossas descobertas contribuem para como as empresas estabelecidas e o CWS podem influenciar a satisfação no trabalho e capacitar para a inovação e o desempenho empresarial.

Gomes, Soares Filho e Miranda (2019) pesquisaram o perfil dos negócios nas empresas de coworking de Palmas/TO, buscando identificar os benefícios que as empresas de coworking em Palmas/TO oferecem aos seus clientes. Foram pesquisados dois coworkings com 11 mensalistas que responderam questões relativas ao tema em estudo. A pesquisa evidenciou que o sistema de coworking já possui muitos adeptos no Brasil e a tendência é se espalhar ainda mais pois esse espaço é uma forma de otimizar os trabalhos e driblar a crise econômica estabelecida no país.

Ramos e Silva (2018) analisara como os coworkings influenciam a cultura de clientes residentes em seus espaços em Manaus/AM. Os resultados da pesquisa evidenciaram uma semelhança no perfil dos coworkings avaliados, vista na predominâcia da Cultura do Clã, com aspectos, como: ambiente familiar, liderança como tutoria e compartilhamento. Os autores perceberam que essas características geram inúmeros benefícios para as empresas residentes, como maior interatividade, produtividade, criação de parcerias, dentre outros.

Diante do exposto, essa pesquisa buscou analisar os projetos de implantação de empresas de coworking na cidade de Teresina - PI, assim, as metas são descrever o modelo de negócio adotado por empresas de coworking, identificando o perfil demográfico dos coworkers, determinando o nível de expectativa dos clientes acerca do serviço de espaços de coworking e o nível de qualidade percebida pelos clientes desses espaços.

\section{Referencial teórico}

A globalização, desde o início do século 21, vem transformando o ambiente empresarial numa atmosfera em que o conhecimento é o principal ativo que uma pessoa, e consequentemente a empresa, deve possuir. Neste contexto, o valor de uma empresa não é medido apenas pelo seu ativo imobilizado ou pela capacidade de geração de lucro, mas também pela competência na criação de conhecimento e inovação. Assim, em tempos conturbados de desaceleração econômica, a manutenção de uma vantagem competitiva baseia-se principalmente na diferenciação e esta é atingida por meio da 
valorização dos indivíduos e suas ideias, bem como em todos os aspectos que possam influenciar na capacidade criativa (Oliveira, Freitas Filho e Lanzer 2016)

É neste contexto que surgem os espaços de coworking, sendo definidos pelo Coworking Brasil (2018) como um movimento de pessoas, empresas e comunidades que buscam trabalhar e desenvolver suas vidas e negócios juntos, para crescer de forma mais rápida e colaborativa", ainda completa que um espaço de coworking é um local ou uma empresa que reúne toda a estrutura de um escritório convencional para que outras empresas ou profissionais se associem ao ambiente e compartilhem toda a organização, incluindo experiências, ideias, rede de contatos e custos, sendo, assim, os gastos são menores comparados a manutenção de um escritório próprio. Assim, os espaços de coworkings representam um modelo para organizações, comunidades ou profissionais liberais trabalharem, por meio do compartilhamento de um mesmo espaço, visando uma redução dos conhecidos e em geral altos custos fixos (Soares e Saltorato, 2015).

Bouncken, Aslam e Qui (2021) consideram que empresas de diversos setores, incluindo gigantes da tecnologia (Microsoft, Google, SAP), telecoms (Orange, AT\&T), e-commerce (Amazon), automadores (MINI) e companhias de seguros (State Farm) tenho investido no principalmente em espaços de coworking internos (Gabor e Lindsay, 2018). As empresas também estão alugando mesas de empresas independentes e aumentando os espaços de coworking para seus funcionários (Spreitzer, Bacevice e Garrett, 2015 )

Neste sentindo Lou e Chan (2020) consideram que os indivíduos trabalham juntos para várias razões: (1) buscar um local de trabalho formal com instalações básicas de trabalho (por exemplo, sala de conferências, impressão e acesso a Wi-Fi), (2) para evite a sensação de isolamento associada a trabalhar sozinho e, em vez disso, procure vizinhos que trabalhem e um senso de comunidade, e (3) para acessar potencial derramamento de conhecimento e colaboração (Spinuzzi, 2012). Os autores destacam que o o senso de comunidade como essencial em espaços de coworking (Capdevila, 2015). Essas interações sociais cara a cara promovem a confiança e o tácito compartilhamento de conhecimento.

Haja vista o crescimento desta atividade, o Brasil ocupa a sétima posição mundial em número de coworkings por país, cujo o líder do top 10 da pesquisa ainda são os EUA, berço do coworking (Cashman, 2012). Ademais, o Censo Coworking Brasil de 2018 manifesta um crescimento acelerado do coworking no Brasil desde 2015, sendo que de 2016 a 2017 ocorreu um avanço abrupto, com o mercado mais que dobrando de tamanho, cerca de 114\% de evolução, e apesar da taxa de 2018 ter decaído para 48\%, o mesmo continua em expansão. Ainda de acordo com o próprio, o estado onde encontra-se um maior número de escritórios com essa nova modalidade de trabalho é São Paulo, registrando 465 espaços, seguido por Rio de Janeiro, com 123. 
Tendo em conta o progresso desse modelo de escritório, é fundamental a compreensão das necessidades do público alvo, suas expectativas, os motivos que o levaram a optar por um espaço de coworking, dentre outros. Por esse ângulo, a "atmosfera social agradável" foi considerada, segundo a revista online alemã Deskmag (Cashman, 2012), como um dos principais motivos para a escolha pelo coworking como modalidade/ambiente de trabalho, em segundo lugar, dentre esses motivos, ficou a "comunidade" e em terceiro a "interação com os outros".

Dessa forma, fornecer um serviço de qualidade pressupõe o atendimento das expectativas dos clientes, para isso, conforme Kotler e Keller (2006), algumas empresas prestadoras de serviços costumam fazer uma análise de desempenho delas mesmas e dos concorrentes, com a finalidade de constatar parâmetros em que o cliente está satisfeito e vice-versa, como comparações com a concorrência, formulário de sugestões e reclamações, compradores misteriosos e pesquisas com os clientes, sendo que, o último é utilizado para avaliar o diversos elementos que compõem o serviço ofertado, realizando um ponderação entre a importância e o desempenho desses, avaliados pela ótica do cliente.

Neste sentido Soares e Saltorato (2015) avaliaram o formato de organização de trabalho denominada coworking na cidade de São Paulo. Para este estudo foram realizadas quatro entrevistas com coworkers, e aplicados questionários junto a 24 indivíduos que trabalham em múltiplos ambientes de coworking. Os resultados evidenciaram que esse sistema se apresenta como uma alternativa interessante para a organização do trabalho em uma cidade do porte de São Paulo, com especial destaque para a inovação e o empreendedorismo, ainda que a gestão dos espaços e dos relacionamentos requeiram maiores considerações.

Zonatto et al. (2017) investigaram o desenvolvimento de competências empreendedoras junto a 49 empreendedores profissionais que atuam em em um dos treze espaços de coworking que estão localizados na cidade de Florianópolis, Estado de Santa Catarina. Os resultados revelaram que os indivíduos participantes da pesquisa, mesmo atuando em um ambiente colaborativo com características similares, apresentaram comportamentos distintos, sendo uns mais e outros menos propensos a interagirem e compartilhar informações entre si, o que vai de encontro ao comportamento esperado para o desenvolvimento de um ambiente colaborativo, capaz de promover o desenvolvimento de competências empreendedoras. As competências empreendedoras com maior destaque foram à Exigência de Qualidade e Eficiência e a Persistência. Já a menos observada evidenciou que a maioria dos empreendedores participantes da pesquisa não planejam suas atividades, não revisam seus planos de trabalho e não mantém registros financeiros, nem mesmo utilizam tais informações para tomar decisões. O não desenvolvimento de tais competências está relacionado a pouca idade da maioria dos empreendedores participantes da pesquisa. Neste estudo, não foi encontrada relação significativa entre 
gênero, horas de trabalho no escritório de coworking e o desenvolvimento de competências empreendedoras.

Com base nisso, foram buscas por pesquisas relacionadas ao coworking no Piauí, por meio de consulta no Portal Capes Periódicos e na base ScienceDirect, com a finalidade de compreender melhor pontos específicos desse negócio na região estudada e realizar comparações com a situação em outros estados. Portanto, este trabalho mostra-se relevante, uma vez que proporciona dados importantes para o desenvolvimento do coworking no Piauí, empreendimento que vêm apresentando uma taxa de crescimento elevada.

\section{Metodologia}

Prodanov e Freitas (2013) considera que a pesquisa básica tem como objetivo gerar conhecimentos novos, úteis para o avanço da ciência, sem qualquer aplicação prática prevista. Envolve, pois, verdades e interesses universais. Desta forma, a pesquisa deste trabalho é classificada como básica, já que busca informações e conhecimentos que poderão, eventualmente, levar a resultados acadêmicos ou aplicações importantes, envolvendo interesses universais.

O método de abordagem empregado na presente pesquisa é o indutivo, pois segundo Lakatos e Marconi (2013), consiste no reconhecimento de leis e teorias a partir da constatação de verdades particulares. E aplicou-se o método monográfico ou estudo de caso como procedimento, o qual, de acordo com os mesmos, expressa um estudo realizado com determinada comunidade, população, grupo ou instituição com o objetivo de delimitar padrões, generalizações e aspectos acerca do tema escolhido. Com base nisso, a metodologia utilizada para o desenvolvimento deste trabalho constará de procedimentos experimentais por etapas, sendo que a primeira etapa abrange a realização de uma revisão bibliográfica. A busca foi realizada no Portal de Periódicos CAPES, disponibilizados gratuitamente e na sua pela Universidade Federal do Piauí - UFPI, a alunos e funcionários da instituição, além disso optou-se também por realizar a pesquisa na base Science Direct por ser uma base acadêmica abrangente e possuir muitos periódicos indexados. As buscas foram realizadas utilizando as palavras chave: "Coworking spaces" e "Coworking". A busca considerou os artigos de 2015 a 2021 (pesquisados no dia 27/01/2021), em inglês e português, sendo considerados apenas artigos de pesquisa e de artigo de revisão. Também foram considerados nesta pesquisa livros e dissertações, com a finalidade de se obter embasamento teórico necessário para a compreensão e produção da pesquisa.

Ademais, conforme Lakatos e Marconi (2013), o levantamento de dados é realizado de maneira a compreender a realidade e verdades parciais, para isso, existem técnicas apresentadas na forma de documentação indireta e direta. Portanto, na segunda etapa utilizou-se a observação direta intensiva e extensiva, por meio de técnicas como a observação não participante e individual a partir de visitas realizadas a estabelecimentos de escritórios compartilhados de Teresina-PI, objetivando a percepção 
de particularidades dos coworkings da região, como serviços ofertados, ambientação, interação entre os usuários, semelhanças e diferenças entre ambos, também realizou-se entrevistas não estruturadas com os gestores dos estabelecimentos visitados com a utilização de um gravador de voz, visando a obtenção de informações necessárias para a compreensão do modelo de negócio das empresas de coworking da região.

Além disso, Gil (1999) elucida que o questionário é uma técnica de pesquisa social relevante, formada por um certo número de questões, no qual tem a finalidade de obter as opiniões, interesses, vivências, expectativas e afins dos indivíduos sobre determinados assuntos. Portanto, essa técnica foi aplicada por meio de perguntas abertas e fechadas aos usuários, com o objetivo de identificar o perfil dos coworkers, características intrínsecas aos espaços de coworking e o nível de qualidade dos escritórios colaborativos avaliados, respondidos sem a presença da pesquisadora, constituindo-se em métodos essenciais à condução desta pesquisa de campo do tipo exploratória. Sendo todos os procedimentos acompanhados de registros fotográficos.

Para Pizoni, Guimarãe e Paladini ( 2018) o viés do questionário compreende questões a respeito do serviço prestado pela empresa e como os donos do empreendimento vêem a proposta do coworking. Desta forma, foram coletadas as informações necessárias para esta pesquisa. Assim, conforme Paladini (2011), são os usuários (coworkers) que determinam o nível de qualidade do serviço utilizado.

Ferrell e Hartline (2009) expõem um método de medição simples utilizando escalas, como a classificação da qualidade dos serviços de arrumação em um hotel variação de ruim a excelente, por meio de uma escala de pontos que vai de 1 a 10. De maneira semelhante, Gianesi e Corrêa (2009) apontam que uma das formas mais usadas para facilitar a coleta e tratamento das medidas de desempenho é a escala Likert, o qual podem ter 3, 5, 7, 9 ou mais pontos, sendo as de 5 e 7 as mais utilizadas, em que os extremos associam-se a "excelente" e "péssimo", "concordo totalmente" e "discordo totalmente" ou outro, como também, os quesitos avaliados podem ser por meio de perguntas diretas ou por afirmativas, em que os clientes concordam ou não com diversos graus.

Para realizar a avaliação da expectativa do cliente na forma de sua percepção da qualidade de excelência de um coworking e o desempenho dos mesmos elementos avaliados do espaço que o coworking utiliza, o presente trabalho fez uso da escala Likert, o qual consiste na atribuição de valores de 1 a 5, que variam desde concordo totalmente até discordo totalmente. Apresentando um total de 18 afirmativas, sendo que 9 delas são voltadas para classificar a qualidade esperada do serviço de coworking, com afirmativas iniciando na forma de "um espaço de coworking de excelência...", bem como, 9 são inclinadas para a avaliação da percepção de qualidade do espaço utilizado pelos coworkers. Por fim, o restante do questionário contém 12 assertivas, também na mesma escala, com intuito de agregar conhecimento à pesquisa. 
Dessa maneira, constituindo a terceira e última etapa, a análise e interpretação desses dados deu-se por meio da realização de uma média aritmética e posterior comparação entre os elementos de qualidade desejada e percebida, além disso, empregou-se gráficos e quadros informativos, assim como, constatação de fatos a fim de proporcionar respostas às investigações. Sintetizando, o ciclo metodológico do presente estudo foi composto por três etapas, as quais se descrevem através de um primeiro momento de revisão bibliográfica, seguido pela coleta de dados, posteriormente partindo para a análise e discussão dos resultados, concluindo a pesquisa com a construção das considerações finais.

Conforme o Censo Coworking Brasil (2018) foram detectados 1194 espaços de coworking no Brasil, sendo que realizando uma pesquisa no site do Coworking Brasil, o qual objetiva divulgar o conceito desse espaço por todo o país desde 2011, não encontrou-se nenhum escritório compartilhado no estado do Piauí, além disso, no Global Coworking Map (2018), o qual faz um mapeamento dos escritórios compartilhados de todo o mundo, identificou-se um total de 252 coworkings no Brasil, contudo, inexistentes no Piauí. Logo, sucedeu-se uma apuração desses espaços por meio do Google Maps, o qual consiste em uma ferramenta disponibilizada pela empresa Google o qual concede mapas e imagens online, e em mídias sociais, sendo possível constatar a existência de 7 espaços com pleno funcionamento.

Os espaços de coworking ainda são poucos na capital, foram identificados 7 espaços, mas apenas 3 foram visitados, os quais serão denominados pelas letras A, B, e C. Realizou-se uma entrevista com os proprietários com finalidade de compreender o modelo de negócio do serviço prestado, bem como analisar viabilidade econômica desse empreendimento em Teresina, além disso, aplicou-se um questionário aos coworkers dos locais visitados. As entrevistas ocorreram nos dias 11, 12 e 19 de dezembro de 2018 e foram gravadas e transcritas. Os demais estabelecimentos de coworkings de Teresina/PI não se mostraram disponíveis devido à ausência do responsável do local no Piauí, a não autorização concedida ao gerente para o desenvolvimento das atividades sugeridas nessa pesquisa ou sem motivo aparente, contudo, solicitou-se o encaminhamento dos questionários por meio de e-mails, não obtendo resultados

Além disso, ainda segundo o Coworking Brasil (2018), encontram-se uma média de 21,2 coworkers residentes por espaço, já no Piauí, por meio das entrevistas e da observação das empresas em funcionamento na presente pesquisa, notou-se um contraste nesse cenário, uma vez que o coworking no Nordeste apresenta-se em uma fase inicial de evolução e é pouco conhecido, por exemplo, dos três estabelecimentos que concordaram com uma visita ao local, aplicação de entrevista aos gestores e questionários aos usuários do serviço, um deles afirma possuir 25 estações e apenas 50\% de ocupação, mostrando um contraste entre a média de coworkers residentes por espaço explanado pelo Coworking Brasil 2018 e as ocupações nas empresas de coworking visitadas de Teresina-PI. Portanto, coletou-se, no total, 21 questionários dos usuários dos serviços dos estabelecimentos 
visitados, sendo que no espaço A e B aplicou-se o questionário para todos os coworkers presentes no local no dia visitado, o qual consiste em 6 e 7, respectivamente, e no espaço C apurou-se 8 questionários.

\section{Resultados e discussão}

\subsection{Entrevista com os gestores dos coworkings}

Foi realizada uma entrevista com os proprietários objetivando compreender o modelo de negócio do serviço prestado, bem como analisar a viabilidade econômica desse empreendimento. A Figura 1 apresenta os espaços do coworking A.

Figura 1

\section{Espaços Coworking A}
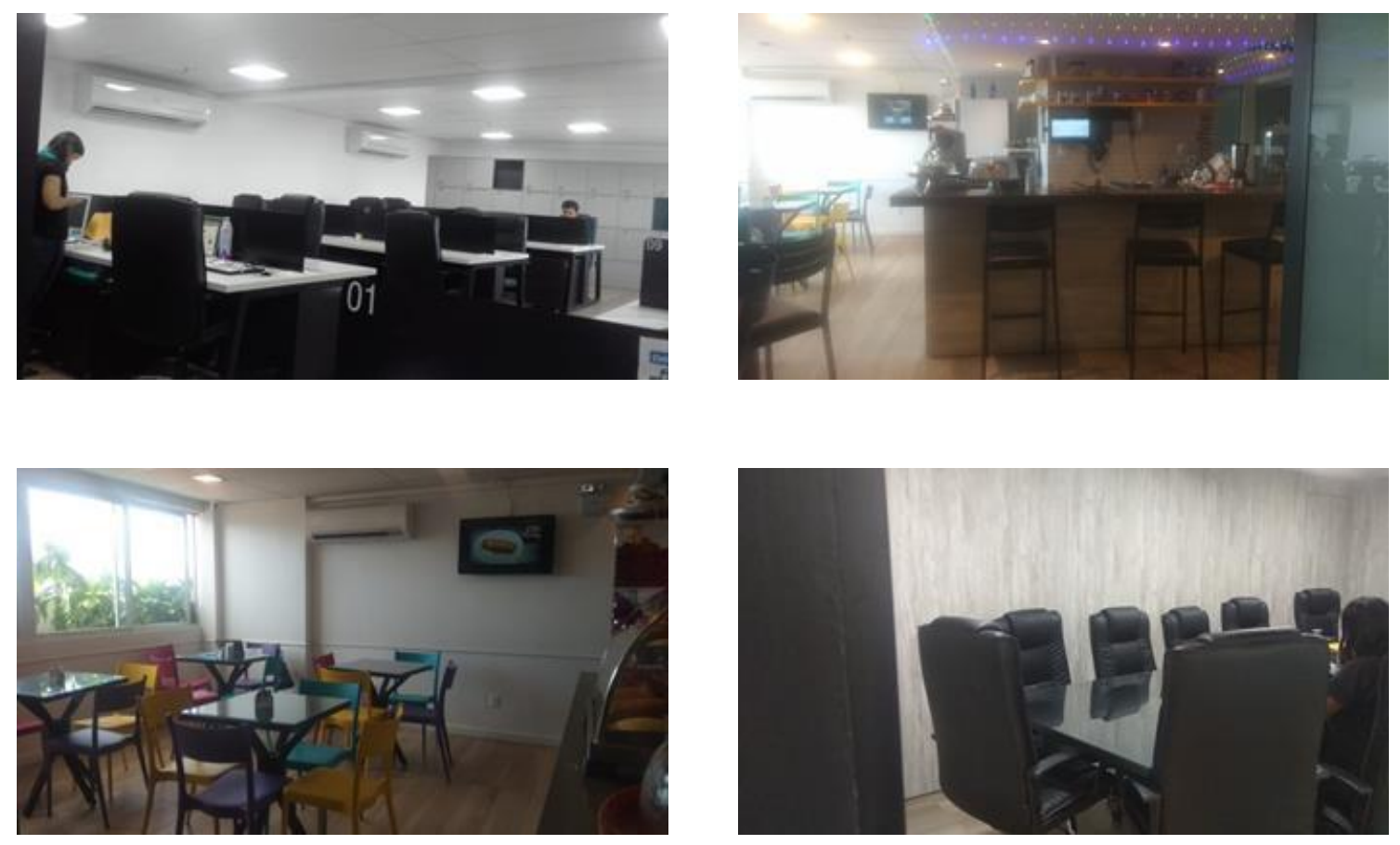

Fonte: Autores (2019).

O espaço, mostrado na Figura 1, apresenta uma boa estrutura de escritório, com recepção, um espaço com cabines individuais, disponibilizando cadeiras, gavetas, armário, lixeira, café e água a vontade, uma copa colaborativa, biblioteca, lanchonete, sala para atender clientes, salas de reunião, oferecendo serviços de limpeza, endereço fiscal, internet e escritório virtual, dispondo de uma telefonista com um número personalizado para cada usuário do coworking, fazendo a entrega de recados e correspondências. Funciona sete dias por semana e está situado em um prédio comercial com 
estacionamento. É formal, contudo exibe uma decoração criativa, moderna, aconchegante, cores neutras nas salas de reunião e de cabines e tons vibrantes em ambientes de convivência, bem como é limpo, organizado e os funcionários são uniformizados.

Questionada em relação a lucratividade do negócio, a gestora considerou a dificuldade de atrair clientes para esse estilo de trabalho, uma vez que há 25 estações de trabalho e apenas 50\% de ocupação, além da questão cultural do teresinense na pouca aceitação e conhecimento do coworking, assim, a proprietária tem buscado investir em mídia social na maneira de explicar o que é e como funciona essa modalidade de trabalho, no entanto, reconhece que negócio vem resultando em prejuízo.

A Figura 2 apresenta os espaços do coworking B.

Figura 2

Espaços coworking B
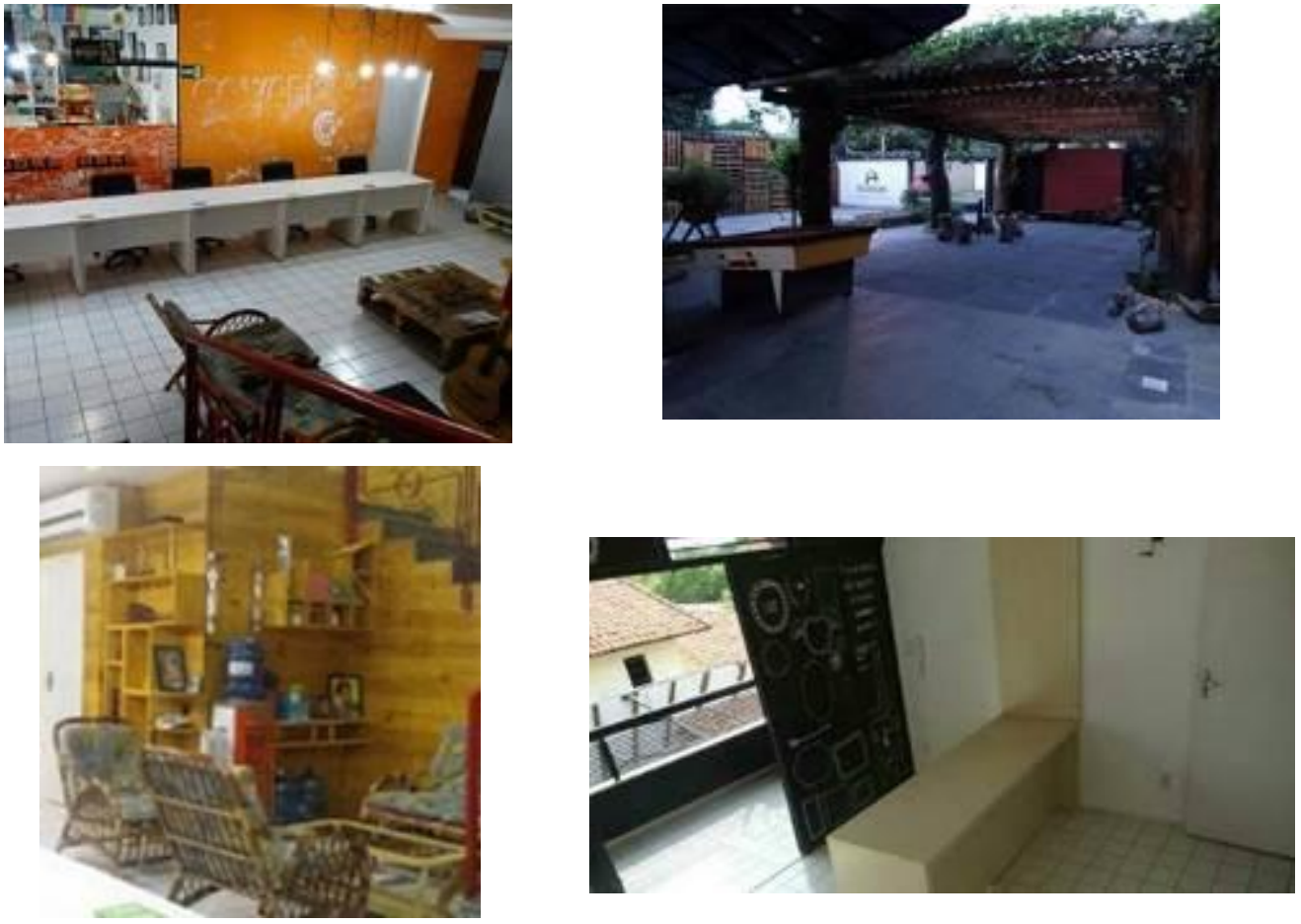

Fonte: Autores (2019).

O coworking B encontra-se em local próximo dos pontos de comerciais e apresenta um modelo híbrido, com cabines individuais compartilhadas com gaveteiro e salas privativas com energia individualizada, possui internet, serviço de limpeza, copa colaborativa, espaço de interação com sinuca e bar, auditório com capacidade para 30 pessoas e projetor. Este coworking dispõe de diversos espaços livres, aberto e arborizados, uma decoração criativa e rústica, pinturas e detalhes com um viés sustentável. O espaço é bastante informal, agradável, envolvido pela natureza, diferente dos escritórios corporativos, marcado pela ausência de um recepcionista e funciona 24 horas, com áreas de convivência 
que corroboram a interação, troca de ideias e desenvolvimento de parcerias entre o público que o frequenta.

O gestor afirma que a ideia inicial era que o coworking fosse autossustentável, visto que o empreendimento é relativamente recente, inaugurado em 2015 e acredita que futuramente esse mercado gerará lucro, mas atualmente se sustenta.

A Figura 3 apresenta os espaços do coworking C, o qual conta com recepção, três espaços com cabines individuais, que disponibiliza cadeiras, lixeiro, gaveta e armário, apresenta também salas privativas, sala de reuniões com oito lugares, sala para atender clientes com seis lugares, copa colaborativa e espaço de interação, todos fechados. São prestados serviços como internet, limpeza, endereço fiscal e comercial, impressão, cópia e digitalização. É localizado em um ponto nobre e comercial da cidade, é moderno, apresentável, formal, corporativo, limpo, a mobília tem aspecto novo, empresarial e sofisticado e os funcionários são uniformizados. Além disso, funciona nos dias úteis e no sábado, sendo fechado no domingo e conta apenas com plano único mensal.

\section{Figura 3}

\section{Espaços coworking C}
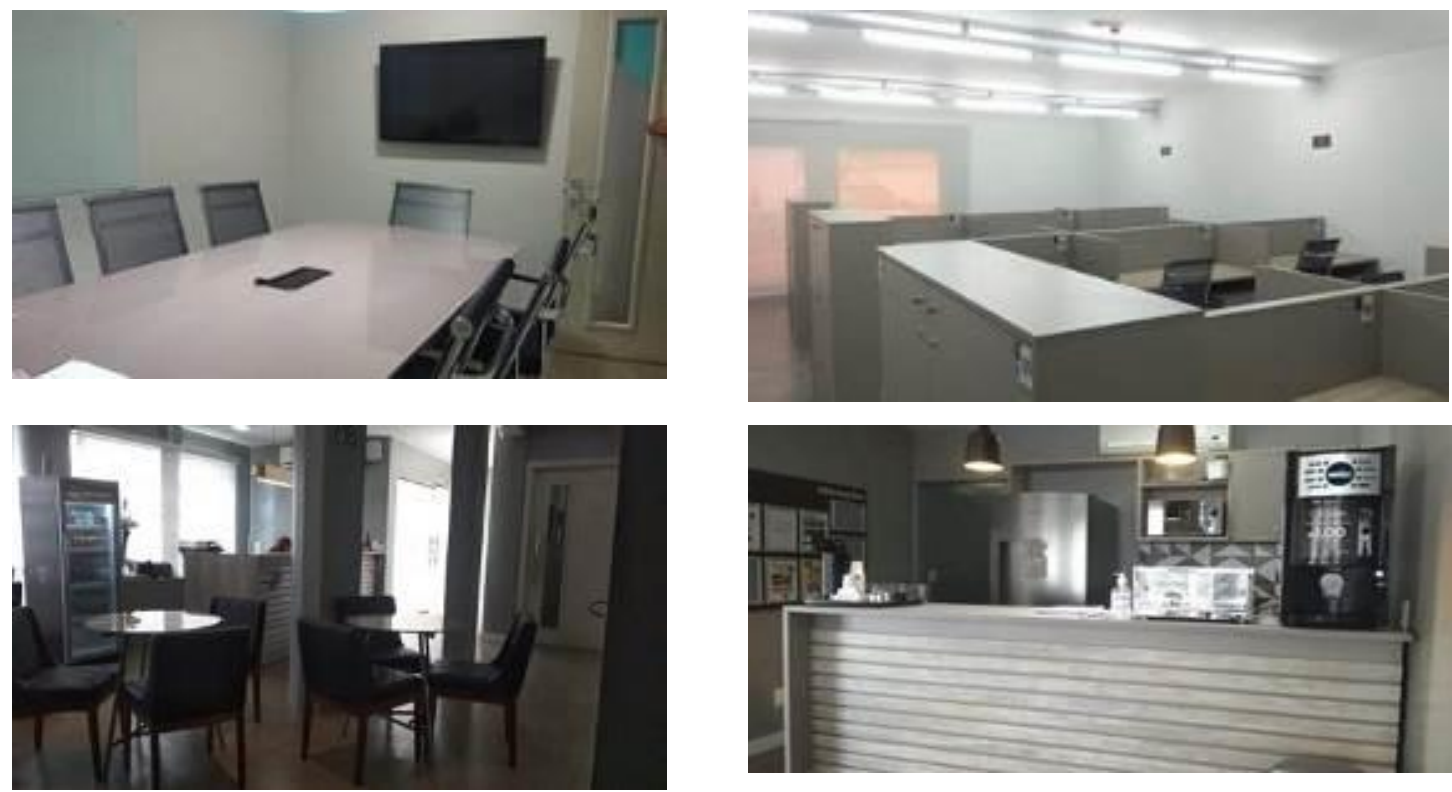

Fonte: Autores (2019).

Indagado em relação a viabilidade do coworking em Teresina, o proprietário declara que mesmo com a visita de possíveis clientes e a aprovação do espaço como um escritório, os usuários não fecham contrato ainda pelo desejo da obtenção da própria instalação ou pelo comodismo de permanência no escritório atual, revelando que a lucratividade do negócio não segue o previsto e que ainda não obteve retorno sob o investimento realizado inicialmente. 
Nesse sentido, foi possível observar a dificuldade de captar clientes, por meio das entrevistas realizadas às empresas de coworking de Teresina, o qual relataram estar tentando trabalhar a cultura comodista do teresinense de adquirir um escritório próprio mesmo com os altos custos de manutenção de um espaço próprio, bem como expandir o conceito do escritório compartilhado pouco conhecido em Teresina, segundo os proprietários. Como estratégia para mudar essa realidade da sociedade teresinense e atrair clientes, há muito investimento em mídia digital.

\subsection{Entrevista com os usuários de coworking}

Por meio da análise de 21 questionários, observou-se um público de 81\% masculino e 19\% feminino, em que atuam em diversas áreas, diferente da pesquisa de Alves (2018), que trata do estudo de comportamento de consumo dos usuários de coworking de Recife, constatando um equilíbrio entre os gêneros, sendo $53,9 \%$ dos usuários do sexo masculino e $46,1 \%$ do sexo feminino. Ainda, $85,72 \%$ apresentam ensino superior completo, 9,52\% ensino superior em curso e 4,76\% tem ensino médio como formação.

Assim, conforme Heckler (2012), por meio da entrevista de 68 coworkers de Porto Alegre, observou-se que $44,12 \%$ possuem o superior incompleto, 11,76\% está cursando a pós-graduação ou MBA e 5,88\% possui algum título de pós-graduação ou MBA. Mostrando que nesse ambiente predominam pessoas com grau de instrução mais elevado, compatível com a faixa etária encontrada na mesma pesquisa, sendo que de 80 respondentes, $72,50 \%$ têm idade entre 20 e 29 anos, 17,50\% de 30 a 39 anos, 7,5\% de 40 a 49 anos e 2,9\% de 0 a 19, dessa forma, revela-se que os consumidores de coworking são pertencentes a geração classificada como Y, mas também apresentando usuários mais velhos. Nesse sentido, na presente pesquisa, em relação a faixa etária, a maioria abrange de 18 a 25 anos, não apresentando nenhum usuário com menos de 18.

Também, demonstrou-se que 57,14\% dos usuários optou por um coworking por meio de uma decisão pessoal, enquanto $42,86 \%$ declarou que a empresa para qual trabalha deseja que o próprio trabalhe nesse ambiente. Heckler (2012) também aborda sobre esse fato, constatando que $64,29 \%$ dos entrevistados optou pelo consumo desse serviço e 35,71\% começaram a trabalhar em um coworking por decisão da empresa.

Ainda, como demonstrado no Gráfico 1, questionados sobre os motivos pessoais ou da empresa para o qual trabalha pela opção de utilização de um espaço compartilhado, dos que responderam, a redução de custos foi citada por 11 dos respondentes, seguido pela possibilidade de compartilhamento de ideias e networking com outros coworkers, indicada 5 vezes. A praticidade e comodidade foram apontados 3 vezes cada, e a segurança 2 vezes. Razões como infraestrutura, boa localização, endereço comercial, flexibilidade de horário e endereço fixo também foram mencionados pelos respondentes, contudo, em menor quantidade, apenas uma única vez. 
Gráfico 1

Motivos apontados pelos coworkers

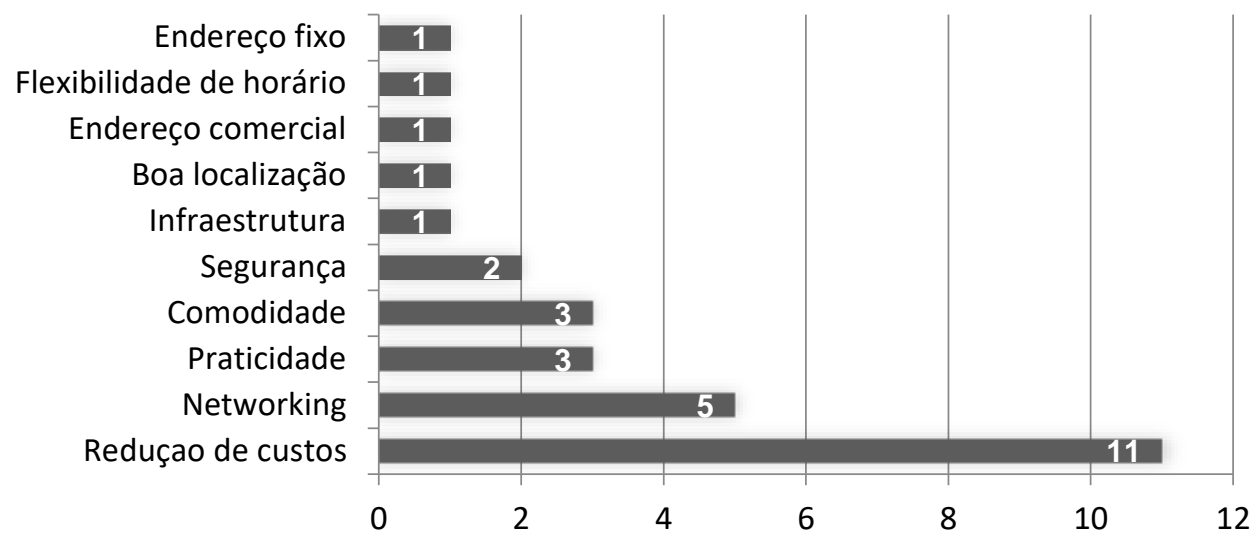

Fonte: Autores (2019).

Na pesquisa de Soares e Saltorato (2015) esses dados são ratificados, uma vez que, por meio da aplicação de 24 questionários a coworkers de 7 espaços do município de São Paulo-SP, constatou-se que a questão do custo configura-se como principal motivo para a escolha desse sistema, seguido por networking, também foram citados pontos como localização e flexibilidade.

Também, segundo Santos e Coelho (2018), com a avaliação de 20 questionários de usuários de um coworking de Belo Horizonte, 70\% deles afirmam ter escolhido o coworking com a intenção de reduzir os custos, uma vez que é possível ter acesso a um escritório completo, salas de reunião, internet e todo o serviço operacional a um custo ínfimo, em segundo, com 35\%, citou-se que "a filial da empresa optou por um espaço de coworking", justificado pelo fato da não preocupação com montagem e custos de um escritório em outro estado ou bairro, por fim, 25\% dos usuários apontou o networking como maneira de fomentar negócios e parceria que não seriam possível em um espaço isolado.

O Gráfico 2 aponta as vantagens dos coworkers, segundo os usuários. 
Gráfico 2

Vantagens apontadas por coworkers

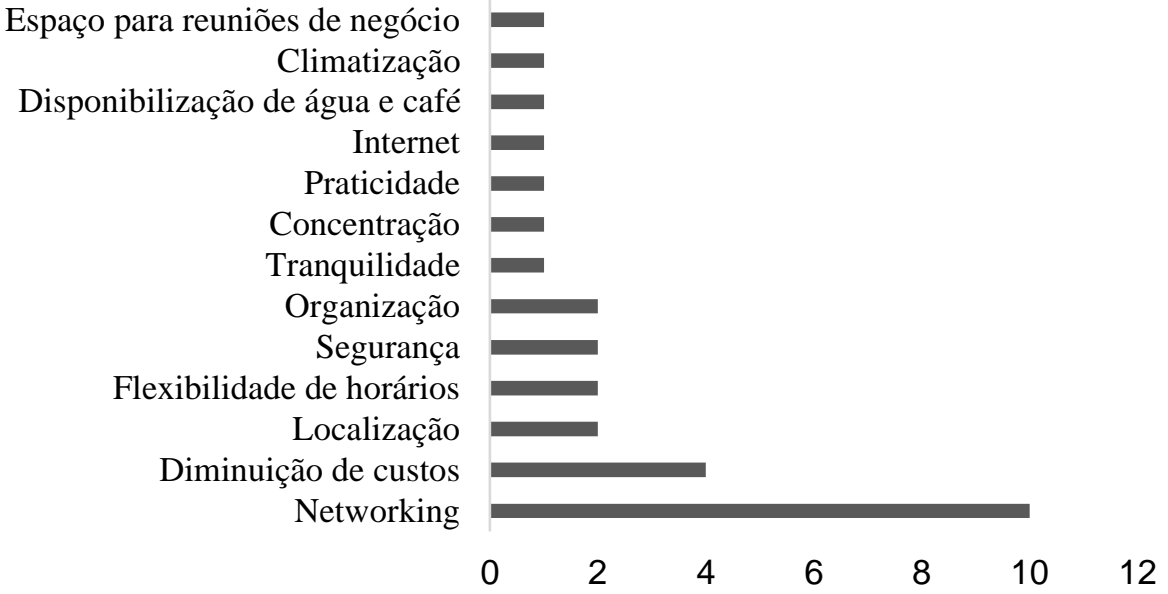

Fonte: Autores (2019)

Das vantagens observadas, como aponta o Gráfico 2, o networking foi o ponto positivo mais citado pelos usuários, sendo um total de 14, como possibilidade de contribuir, aprender e interagir com outras pessoas de outras áreas, de cooperar com outros serviços e atividades, de captar clientes, de fazer negócios e devido a rotatividade de pessoas no local, além disso, a redução de custos na manutenção de um escritório pelo compartilhamento de despesas foi o segundo ponto mais mencionado (8 vezes), seguidos por segurança (4 vezes), infraestrutura completa de escritório (3 vezes), flexibilidade de horários (3 vezes), praticidade (3 vezes), também, localização privilegiada, organização e tranquilidade foram citados, obtendo a mesma quantidade de ocorrências (2 vezes), por fim, benefícios como internet, disponibilização de água e café, climatização, concentração, conforto, comodidade e espaços para reuniões de negócio também foram apontados (1 vez).

Nesse sentido, Carneiro e Camilo (2015), o qual aplicaram questionários a 35 usuários de cinco estados diferentes, três da região Sul e dois da região Sudeste do país, listaram 18 características mais comumentes relacionada aos coworkings e solicitaram aos participantes da pesquisa que indicassem cinco principais pontos positivos, assim, obtendo que a principal vantagem do coworking é o fortalecimento do networking (60\%), constatando que a rede de relacionamentos é um fator de extrema relevância e motivador do consumo, seguido de otimização de custos e economia (51,4\%), ambiente agradável dos espaços de coworking $(45,7 \%)$, compartilhamento do conhecimento $(34,3 \%)$ e convívio social mais intenso $(28,6 \%)$

O Gráfico 3 aponta as desvantagens dos coworkers de acordo com os usuários entrevistados. 


\section{Gráfico 3}

Desvantagens apontadas por coworkers

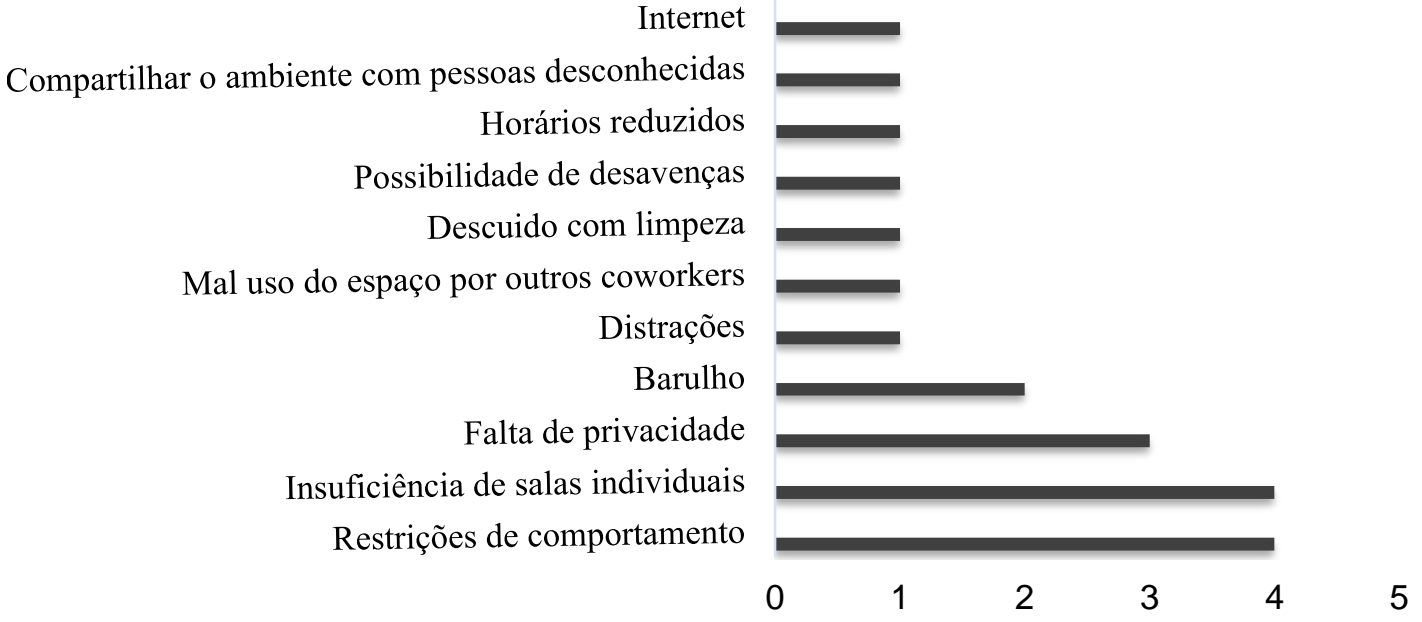

Fonte: Autores (2019)

O Gráfico 3 revela as desvantagens observadas por coworkers e a frequência em que as mesmas foram apontadas, dessa maneira, restrições de comportamento e insuficiência de salas individuais configuram-se como ponto negativo mais citado, do primeiro, coworkers afirmaram, principalmente, o fato de terem que mediar o tom de voz como forma de proporcionar o silêncio no ambiente, caracterizando-se como fator desagradável, especialmente para os que trabalham com comunicação, já em relação ao segundo, os coworkers citaram ser inconveniente não haver salas privativas para reuniões rápidas com colaboradores, equipes e clientes sem custos adicionais.

Em seguida, apontaram falta de privacidade e barulho como pontos negativos do escritório compartilhado. Distrações, mal uso do espaço por outros coworkers, descuido com limpeza, possibilidade de desavenças e horários reduzidos também foram mencionados de forma amena, sendo este último atribuído a indisponibilidade do espaço ou reduzida em finais de semana e feriados em alguns coworkings. Compartilhar o ambiente com pessoas desconhecidas, antes apresentado como uma vantagem para trocar ideias, aprender com outras pessoas de diferentes áreas e ampliar a rede de contatos, assim como internet foram igualmente citados como desvantagens, a internet referiu-se a problemas estruturais por ser um instrumento de trabalho muito importante e o usuário exigir qualidade desse serviço, além disso a limpeza e organização mostram-se quesitos relevantes para a qualidade do coworking.

Carneiro e Camilo (2015) questionaram aos coworkers pesquisados se haveria dificuldades em fazer parte desse espaço, verificando que $88,6 \%$ dos profissionais não encontraram dificuldades ou não 
perceberam aspectos negativos, por outro lado, 11,4\% afirmaram encontrar, justificadas nas interrupções que existem nos ambientes de coworking decorrentes do convívio dessas pessoas no mesmo espaço, como conversas por telefone, diálogos entre os coworkers no escritório, o que acabam por influenciar na concentração dos demais.

Além disso, indagou-se como que os coworkers conheceram o coworking que utilizam atualmente, como evidenciado no Gráfico 4, assim, a maioria deles, 38\%, conheceu por meio da indicação de um amigo ou conhecido, mostrando o quanto é eficiente e importante o "boca a boca" nesse ramo de negócio como forma de captar clientes, seguido do conhecimento mediante a empresa o qual o usuário trabalha com 29\%. Busca na internet pelo próprio coworkers e ação online realizada pela empresa, como rede sociais, o qual consiste no principal canal para chegar aos clientes utilizado pelas empresas de coworking, apresentaram-se com $14 \%$ cada e outros com $5 \%$.

Gráfico 4

Como o coworkers conheceu o coworking utilizado

"Buscando pela internet
o qual trabalho
o meio da(s) empresa(as)
um amigo/conhecido
um eio da indicação de
escritório
$=$ Outros

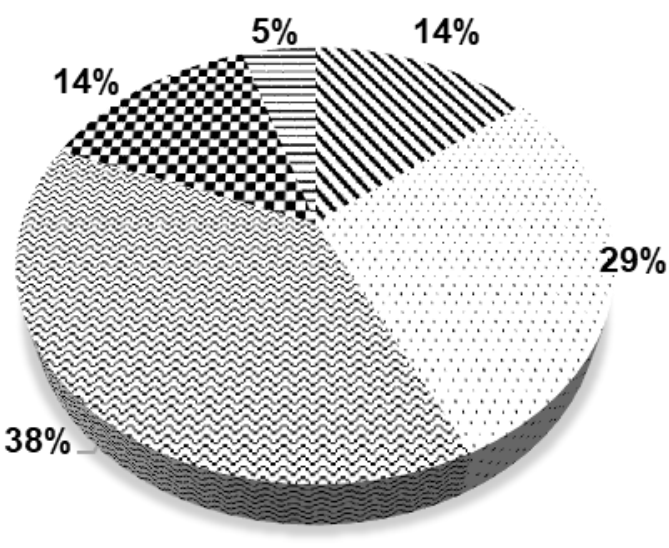

Fonte: Autores (2019)

Heckler (2012) ratifica esse fato com a verificação de como as pessoas obtêm informações a respeito do coworking, percebendo que 30\% conheceram o espaço por meio de um amigo ou conhecido, 22\% por intermédio da empresa o qual trabalha, 15\% por meio de buscas realizadas na internet, $13 \%$ através de contatos comerciais efetuados pela empresa prestadora do serviço e $10 \%$ por meio da promoção de eventos e divulgação do escritório. Assim como no artigo de Carneiro e Camilo (2015), o qual constataram que 51\% dos participantes da pesquisa afirmaram que conheceram o coworking por meio de seus contatos e redes de amigos ou colegas.

Com a finalidade de esboçar o modelo de negócio adotado por empresas de coworking, adicionou-se, ao questionário respondido pelos coworkers, afirmações referentes a parâmetros 
considerados relevantes a uma empresa de coworking, constatados por meio das pesquisas bibliográficas realizadas. Nesse segmento, utilizou-se a escala Likert para avaliar o nível qualidade esperada pelo cliente acerca dos serviços de coworking, bem como classificar o nível percebido das mesmas considerações. As respostas variam de 1 a 5, o qual "1" refere-se a "concordo totalmente" e "5" a "discordo totalmente", além disso, o número "3" atribui-se a "não concordo, nem discordo", dessa maneira, realizou-se uma média aritmética com as respostas obtidas, logo, quanto mais próximo de "1" o nível de concordância com determinada afirmação, maior o grau consentimento com a mesma, assim como, quanto mais próximo de " 5 ", menor o grau de concordância.

O Quadro 1 apresenta o nível de consentimento com as assertivas referentes à expectativa de um espaço de coworking de excelência.

\section{Quadro 1}

Expectativa de um espaço de coworking de excelência

\begin{tabular}{|l|l|}
\hline $\begin{array}{l}\text { Um espaço de Coworking de excelência apresenta uma recepção/atendimento para coworkers e } \\
\text { seus clientes com simpatia e local bem apresentável. }\end{array}$ & 1.09 \\
\hline Um espaço de Coworking de excelência preza pela limpeza e organização. & 1.09 \\
\hline $\begin{array}{l}\text { Um espaço de Coworking de excelência estimula ao compartilhamento e a troca de ideias e } \\
\text { informações entre os coworkers (colaborativismo). }\end{array}$ & 1.19 \\
\hline Um espaço de Coworking de excelência oferece internet de qualidade. & 1.19 \\
\hline Um espaço de Coworking de excelência oferece serviços office. (impressora, fax, scanner) & 1.24 \\
\hline Um espaço de Coworking de excelência promove a redução de custos na manutenção de um & 1.28 \\
\hline escritório. & 1.28 \\
\hline Um espaço de Coworking de excelência apresenta uma infraestrutura completa de escritório. & 1.33 \\
\hline Um espaço de Coworking de excelência apresenta espaços amplos, abertos e salas de reunião. & 1.33 \\
\hline Um espaço de Coworking de excelência localiza-se em uma região bem vista. & \\
\hline
\end{tabular}

Fonte: Autores (2019)

Assim, o grau de concordância com os parâmetros de um serviço de coworking com qualidade de excelência atingiram médias próximas de "1", ou seja, concordo totalmente, demonstrando uma elevada expectativa em relação às afirmações efetuadas. Os quesitos com maior relevância para um espaço de coworking de excelência, foram recepção e atendimento aos clientes com simpatia e um local apresentável, além de limpeza e organização, ambos com média 1.09.

O Quadro 2 apresenta os resultados da percepção dos usuários quanto a qualidade dos escritórios compartilhados utilizados pelos respondentes, em que manteve-se médias próximas de 1 e 
de 2, ou seja, a maioria dos usuários de coworking concorda totalmente com algumas afirmativas feitas e outros concordam em parte, respectivamente.

\section{Quadro 2}

Percepção dos usuários quanto ao espaço utilizado

\begin{tabular}{|l|l|}
\hline $\begin{array}{l}\text { O espaço de Coworking o qual utilizo apresenta uma recepção/atendimento para coworkers e seus } \\
\text { clientes com simpatia e local bem apresentável. }\end{array}$ & 1.47 \\
\hline O espaço de Coworking o qual utilizo preza pela limpeza e organização. & 1.47 \\
\hline $\begin{array}{l}\text { O espaço de Coworking o qual utilizo estimula ao compartilhamento e a troca de ideias e } \\
\text { informações entre os coworkers (colaborativismo). }\end{array}$ & 1.71 \\
\hline O espaço de Coworking o qual utilizo oferece internet de qualidade. & 1.52 \\
\hline $\begin{array}{l}\text { O espaço de Coworking o qual utilizo oferece serviços office. (impressora, fax, scanner) } \\
\text { O espaço de Coworking o qual utilizo promove a redução de custos na manutenção de um }\end{array}$ & 1.80 \\
\hline $\begin{array}{l}\text { O espritório. } \\
\text { O espaço de Coworking o qual utilizo apresenta espaços amplos, abertos e salas de reunião. }\end{array}$ & 1.47 \\
\hline O espaço de Coworking o qual utilizo localiza-se em uma região bem vista. & 1.42 \\
\hline
\end{tabular}
Fonte: Autores (2019)

Nesse sentido, as questões de disposição de serviços office, compartilhamento e a troca de ideias entre os coworkers e a internet de qualidade foram os parâmetros de qualidade percebida avaliados com médias mais próximas de 2, isto é, "concordo em parte", sendo, na devida ordem, 1.80, 1.71 e 1.52. Por outro lado, os outros critérios como os espaços amplos, abertos e salas de reunião, localização em região bem vista, infraestrutura de escritório completa, redução de custos na manutenção de um escritório, limpeza e organização, além de recepção/atendimento com simpatia e ambiente bem apresentável foram melhor avaliados quanto a percepção, com médias 1.24, 1.24, 1.42, 1.47. 1.47 e 1.47 , respectivamente.

Após obter uma média de expectativa e desempenho para cada assertiva de qualidade, realizouse a diferença entre ambas, efetuando a subtração de desempenho menos a expectativa, visando verificar se as empresas de coworking de Teresina-PI atendem às expectativas dos coworkers da região, como mostra o Quadro 3. 


\section{Quadro 3}

Diferença entre desempenho e expectativa

\begin{tabular}{|l|l|}
\hline Boa recepção/atendimento e local apresentável & 0.38 \\
\hline Limpeza e organização & 0.38 \\
\hline Networking e colaborativismo & 0.52 \\
\hline Internet de qualidade & 0.33 \\
\hline Serviços office & 0.56 \\
\hline Redução de custos na manutenção de um escritório & 0.19 \\
\hline Infraestrutura completa de escritório & 0.14 \\
\hline Espaços amplos, abertos e salas de reunião & -0.09 \\
\hline Boa localização & -0.09 \\
\hline
\end{tabular}

Fonte: Autores (2019).

De acordo com o Quadro 3, observa-se que as diferenças que apresentam um resultado igual a zero, presume-se que a expectativa do usuário é atendida naquele determinado tópico, já se o resultado for maior que zero, entende-se que neste item ocorreu com qualidade abaixo do esperado pelo cliente, por fim, caso ocorra uma diferença negativa, assimila-se que as expectativas do cliente foram superadas no quesito avaliado. Vale ressaltar que diferenças pequenas e positivas também são consideradas aceitas para a satisfação do cliente.

A maioria dos quesitos avaliados tiveram valores maiores que zero, contudo, bem próximos do mesmo, isto é, atendem aos critérios de satisfação do cliente, portanto os parâmetros como a infraestrutura completa de um escritório e a promoção da redução de custos na manutenção de um escritório foram os melhores avaliados pelos usuários com uma diferença entre desempenho e expectativa de 0.14 e 0.19, respectivamente. Outros, como a concessão de uma internet de qualidade, bom atendimento ao cliente com um local apresentável e um ambiente limpo e organizado, exibiram resultados igualmente aproximados da satisfação do cliente.

A disponibilização de serviços office e o estímulo ao networking foram os itens que demonstraram uma maior diferença, todavia, apesar de serem questões que merecem maior atenção, podem ser consideradas satisfatórios para o consumidor. Por fim, o ponto de boa localização e a disposição de espaços amplos, abertos e salas de reuniões apresentaram ambos valores negativos, evidenciando uma leve superação das expectativas dos usuários de coworking. Disso, depreende-se que as empresas de escritório compartilhado de Teresina oferecem uma qualidade aceitável aos clientes. 


\section{Conclusão}

O presente trabalho teve como objetivo analisar as particularidades dos ambientes de escritório compartilhado de Teresina-PI, avaliando como o mesmo funciona, suas instalações, estrutura, vantagens e desvantagens, logo, por meio da visita em três espaços de coworking em Teresina foi possível determinar essas singularidades e compreender qual a evolução desses coworkings em relação a outros espaços de escritório compartilhado no Brasil. Percebendo que o coworking em Teresina encontra-se em fase inicial de instituição e que apresenta dificuldades na captação de clientes, devido a questão cultural do teresinense de preferir adquirir um escritório próprio apesar dos altos custos de manutenção envolvidos e a baixa difusão de conhecimento do coworking, não havendo uma grande aceitação desse novo estilo de trabalho. Portanto, os gestores investem nas mídias sociais como forma de apresentar essa modalidade inovadora de escritório compartilhado.

Além disso, propôs-se depreender o modelo de negócio das empresas que prestam esse serviço, ressaltando o perfil de clientes, perspectiva dos proprietários diante do mercado e dificuldades do empreendimento, tendo obtido sucesso na coleta desses dados, permitindo o entendimento de pontos relevantes de um projeto de instalação de um coworking e a assimilação de possíveis problemas existentes, assim, servindo como referência para instituição de novos empreendimentos e como autocrítica às já existentes que buscam desenvolver seus negócios.

Por fim, esta pesquisa tencionou para avaliação da qualidade dos escritórios compartilhados de Teresina, realizando uma análise quantitativa entre o que se espera de um serviço prestado, ou seja, a expectativa, e como esse serviço é realmente realizado, isto é, a percepção dos clientes. Logo, com essas informações é viável tomar decisões com mais segurança, responsabilidade e estratégia, como alocar investimento, saber em que investir, compreender pontos fracos que necessitam de melhora e pontos fortes que não demandam grande atenção. Dessa forma, as possibilidades de desenvolver estratégias de marketing e de captação de clientes mais eficientes se expandem, como dedicar atenção a um público alvo específico que proporcione um retorno mais significativo a empresa, bem como de cativar e conquistar o consumidor, para que, assim, o mesmo torne-se fiel ao coworking usado.

As limitações desta pesquisa incluíram, primeiramente, localizar os estabelecimentos de escritório compartilhado em pleno funcionamento em Teresina-PI, uma vez que, devido o empreendimento ser relativamente recente na região, não foi possível encontrá-los por meio dos sites especializados nas buscas por coworkings no Brasil e no Mundo, como o site Coworking Brasil e o Global Coworking Map, portanto, como solução, buscou-se mapeá-los por meio de pesquisas em redes sociais e no Google Maps. A segunda dificuldade refere-se a concessão de autorização das empresas para a realização da visita com objetivos explanados, em que a maioria não aceito, por fim, a com os coworkers engloba a própria disposição dos mesmos em colaborar com o trabalho, além das visitas terem ocorrido 
em dias e horários específicos, o que dificultou a abordagem de todos os consumidores dos estabelecimentos visitados.

\section{Referências}

Alves, R. C. A. Consumo colaborativo e valores pessoais: um estudo sobre o comportamento de consumo dos usuários de coworking em Recife. 2018. Trabalho de Conclusão de Curso, Universidade Federal do Rio Grande do Norte, Natal, RN,2018. https://repositorio.ufrn.br/handle/123456789/34915

Alves, S. Avaliaçāo da qualidade do serviço de espaços de coworking utilizando o modelo Servqual. 2016. Trabalho de Conclusão de Curso, Pontifícia Universidade Católica do Rio de Janeiro, Rio de Janeiro, RJ, 2016. Disponível: https://www.maxwell.vrac.pucrio.br/colecao.php?strSecao=resultado\&nrSeq=31380@1

Bouncken, R.B.; Aslam, M. M.; Qiu,Y. Coworking spaces: Understanding, using, and managing sociomateriality, Business Horizons, v. 64 , n.1, p.119-130, 2021. https://www.sciencedirect.com/science/article/pii/S0007681320301257

Brown, J. Curating the "Third Place"? Coworking and the mediation of creativity, Geoforum, v. 82, p. 112-126, 2017. https://www.sciencedirect.com/science/article/pii/S0016718517300866

Capdevila, I. Coworking spaces and the localized dynamics of innovation in Barcelona. Int. J. Innov. Manag. v. 19 , n.3, p. 1-25, 2015. https://papers.ssrn.com/sol3/papers.cfm?abstract_id=2502813

Carneiro, R. G.; Camilo, E. Coworking: Redes de relacionamento, pontos positivos e negativos do modelo organizacional. Anais do // Encontro Internacional de Gestão, Desenvolvimento e Inovação (EIGEDIN), 2018, v. 2 n. 1 Naviraí, Mato Grosso do Sul, Brasil. https://periodicos.ufms.br/index.php/EIGEDIN/article/view/7100

Cashman, A. 2000 Coworking Spaces worldwide. Deskmag, 2012. http://www.deskmag.com/en/2000coworking-spaces-worldwide-617 
Coworking Brasil. Plataforma colaborativa sobre coworking. 2018. https://coworkingbrasil.org/o-quee-coworking./

Coworking Brasil. Censo Coworking Brasil 2016. Recuperado em 01 dezembro, 2018, de https://coworkingbrasil.org/censo/2018

Ferrell, O. C.; Hartline, M. D. (2009). Estratégia de Marketing. (4a ed.). São Paulo: Cengage Learning. $624 p$.

Florida, R.; Adler, P.; Mellander, C. The city as innovation machine. Reg. Stud. v. 51, p. 86-96, 2017. https://www.tandfonline.com/doi/full/10.1080/00343404.2016.1255324.

Gabor, N.; Lindsay, G. Why companies are creating their own coworking spaces. Harvard Business Review, v. 2, n. 10, p.1-7, 2018. https://hbr.org/2018/09/why-companies-are-creating-theirown-coworking-spaces.

Gianesi, I. N.; Corrêa, H. L. (2009). Administração estratégica de serviços: operações para satisfação do cliente. (1a. ed.) São Paulo: Atlas. 240p

Gil, A. C. (1999). Métodos e técnicas de pesquisa social (5a.ed.) São Paulo: Atlas. 220p

Gomes, D. H.; Soares Filho, V.; Miranda, P. V. Economia Colaborativa: perfil das empresas de coworking em Palmas (Tocantins). (2020). FOCO: Rev. Foco. v.13, e4754, p. 1-26, 2020. https://focopublicacoes.com.br/foco/article/view/257/pdf.

Global Coworking Map. Plataforma de mapeamento de todos os espaços de coworking do mundo. 2018. https://coworkingmap.org.

Heckler, H. Pesquisa de comportamento de consumo de escritórios de coworking. 2012. Trabalho de Conclusão de Curso, Universidade Federal do Rio Grande do Sul, Porto Alegre, RS, 2012. https://www.lume.ufrgs.br/handle/10183/67460.

Kotler, P.; Keller, K. L. (2006). Administração de marketing (12a ed). São Paulo: Pearson Prentice Hall. $750 p$

Lakatos, E. M.; Marconi, M. A. (2007). Fundamentos da metodologia científica (7a ed.) São Paulo: Atlas. $297 p$ 
Luo, Y.; Chan, R. C.K. Production of coworking spaces: Evidence from Shenzhen, China, Geoforum, v. 110, p. 97-105, 2020. https://www.sciencedirect.com/science/article/pii/S0016718520300087

Medina, P. F.; Krawulskl, E. Coworking como modalidade e espaço de trabalho: uma análise bibliométrica. Cadernos de Psicologia Social do Trabalho. v.18 n.2, p. 181-190, 2015 http://dx.doi.org/10.11606/issn.1981-0490.v18n2p181-190.

Moriset, B. Building new places of the creative economy. The rise of coworking spaces. In: Presented at 2nd Geography of Innovation International Conference, Utrecht, January 23-25, 2014. https://shs.hal.science/halshs-00914075.

Oliveira, F. V.; Freitas Filho, F. L.; Lanzer, E. A. Espaços de Coworking como Fomentadores ao Ecossistema Empreendedor: O caso brasileiro do CUBO. Revista ESPACIOS. v. 37, n. 27, p. 1931, 2016. https://www.revistaespacios.com/a16v37n27/16372720.html Paladini, E. P. (2011). Avaliação estratégica da qualidade (2a ed.) São Paulo: Atlas. 256p. Pizoni, R.; Guimarães, J. P.; Paladini, E. P. (2019). Método de avaliação da qualidade para ambientes e trabalho compartilhado. NAVUS Revista de Gestão e Tecnologia, v. 9, n.1, p.122-135, 2019. https://www.researchgate.net/publication/330066791_Metodo_de_avaliacao_da_qualidade_ para_ambientes_e_trabalho_compartilhado

Prodanov, C. C.; Freitas, E. C. (2013). Metodologia do trabalho científico [recurso eletrônico]: métodos e técnicas da pesquisa e do trabalho acadêmico. (2a. ed.) Novo Hamburgo: Feevale. 299p SANTOS, M.; COELHO, A. P. G. B. Coworking como novo modelo de negócio: um estudo de qualidade percebida pelo consumidor e suas expectativas. Revista Pensar: Gestão e Administração, Belo Horizonte, v. 6, n. 2, jan. 2018. http://revistapensar.com.br/administracao/pasta_upload/artigos/a180.pdf.

Slack, N.; Chambers, S.; Harland, C.; Harrison, A.; Johnston, R. (2011). Administração da Produção: Edição Compacta. São Paulo: Atlas. 528p

Serra, A. Coworking: Uma nova perspectiva mercadológica para São Luís. 2013. Trabalho de Conclusão 
de Curso - Curso de Administração, Universidade Federal do Maranhão, São Luís, MA, 2013. https://monografias.ufma.br/jspui/handle/123456789/974

Soares, J. M. M.; Saltorato, P. Coworking, uma forma de organização de trabalho: conceitos e práticas na cidade de São Paulo. AtoZ: Novas práticas em informação e conhecimento, v. 4, n.2, p. 6173, 2015.

https://revistas.ufpr.br/atoz/article/view/42337\#: :text=Introdu\%C3\%A7\%C3\%A30\%3A\%20es te\%20estudo\%20teve\%20como,relativos\%20ao\%20local\%20de\%20instala\%C3\%A7\%C3\%A3o

Spinuzzi, C. Working alone together: coworking as emergent collaborative activity. J. Bus. Tech. Commun. V. 26, p.399-441, 2012. https://www.researchgate.net/publication/258143922_Working_Alone_Together_Coworking _as_Emergent_Collaborative_Activity

Spreitzer, G. M.; Bacevice, P.; Garrett, L. Why people thrive in coworking spaces. Harvard Business Review, v. 93, n. 7, p 28-30, 2015. https://deskchairworkspace.com/why-people-thrive-incoworking-spaces/

Ramos, A. B.; Silva, F. M. V. Análise da influência da cultura de coworkings na cultura organizacional de clientes residentes. Revista Brasileira de Gestão e Inovação - Brazilian Journal of Management \& Innovation. v. 6, n. 2, p. 48-75, 2019.

http://www.ucs.br/etc/revistas/index.php/RBGl/article/view/6002/pdf

Reuschke, D.; Clifton, N.; Fisher, M. Coworking in homes - Mitigating the tensions of the freelance economy. Geoforum. v. 119, p. 122-132, 2021. https://www.sciencedirect.com/science/article/pii/S0016718521000051

Zonatto, P. A. F.; Sbissa, A. P.; Lenzi, F. C.; Zonatto, V. C. S. Desenvolvimento de competências empreendedoras em ambiente colaborativo: Uma análise com profissionais que atuam em escritórios de coworking/entrepreneurial competences development in collaborative environment: an analysis with professional acting in coworking offices. REAT - Revista Eletrônica de Administração e Turismo. v. 10, n. 5, p.1132-1152, 2017 
Oliveira, C. M. R., \& Santos, M. S. F. (2023, jan./mar). Análise das empresas de coworking de Teresina-PI

https://periodicos.ufpel.edu.br/ojs2/index.php/AT/article/view/10425/7350

Waters-Lynch, J.; Potts, J.; Butcher, T.; Dodson, J.; Hurley, J. Coworking: A transdisciplinary overview.

2016). https://papers.ssrn.com/sol3/papers.cfm?abstract_id=2712217 